\title{
Riding on the Coat-Tails of Traditional Cultural Expressions
}

\author{
Luminița Olteanu ${ }^{1,2}$ (1)
}

Published online: 20 May 2020

(c) The Author(s) 2020

\begin{abstract}
Matters related to the protection of traditional cultural expressions ('TCEs') or expressions of folklore ('EoFs') are sensitive and intricate as a blend of legal, economic, philosophical and anthropological considerations jostle to capture their core features. This results in disparate views surrounding what should qualify as TCEs or EoFs, who should be considered their 'owner' (assuming that ownership per se is conceptually compatible with these items), which is the most appropriate legal protection regime and how broad their scope of protection should be. Drawing from these various accounts on TCEs, this article focuses on the interaction between TCEs and EoFs originating on the European continent and the European Union ('EU') trade mark legislation. Specifically, this article examines whether the limitations of the effects of trade mark rights and of the absolute grounds of refusal, as developed by the case law of the Court of Justice of the European Union, are effective in preserving the cohesion of TCEs. This article advances the thesis that registration of TCEs and EoFs as trade marks generates an imbalance between the rights of the trade mark owner and the defences available to others under the EU trade mark law framework. Furthermore, such an imbalance is likely to hinder the unfettered circulation of TCEs and undermine their original meaning. Lastly, in some cases, trade mark registration of TCEs contributes to their appropriation and misappropriation. The article concludes that, de lege ferenda, the direct exclusion of TCEs as eligible subject matter for trade mark registration is preferable to seeking a post factum remedy.
\end{abstract}

Keywords Traditional cultural expressions · Free riding · Dilution · Cultural appropriation $\cdot$ Trade marks

Luminița Olteanu

1.olteanu@kent.ac.uk

1 Kent Law School, University of Kent, Canterbury, UK

2 UCL Laws, London, UK 


\section{Introduction}

'We seem as a species to be driven by a desire to make meanings: above all, we are surely homo-significans - meaning-makers' [22, p. 13].

One month before the 2014 presidential elections in Romania [8], both social media and the conventional press were saturated with election related messages, slogans and advertisements. One of the then candidates used traditional Romanian decorative folkloric patterns on his electoral posters accompanied by slogans such as 'Proud to be Romanians'. Besides the ignored legal prohibition on use of the colours of the Romanian flag on campaign materials - which was clearly breached-I felt instinctively that there was something else 'wrong' with the way this campaign was carried out. The use of traditional Romanian patterns disturbed me in a manner which is difficult to explain, giving rise to a sense or 'feeling of lost authenticity' $[23$, p. 4$]$ in my mind. This visual encounter and the way such signs are used to convey messages to the public made me think about trade marks. Should certain TCEs should be considered 'off limits' in terms of registration under the EU trade mark law? This is how the research question of this article surfaced.

I attempt to respond to this question first by examining, in section two, the various definitions given to TCEs, their main features and the justifications underpinning the need to preserve their original meaning. I also consider the nexus between the European EoFs, cultural heritage and the commitment of the EU and that of the Council of Europe to safeguarding TCEs. Next, in section three, I demonstrate that while the EU should ensure the cohesion of TCEs, in practice EU trade mark legislation grants trade mark owners rights which permit them to significantly alter the original meaning of TCEs. I argue that a systemic interpretation of the absolute grounds of refusal contained in trade mark law and of the legislation committed to safeguarding the European cultural heritage could be employed successfully to preserve the original meaning of TCEs. In section four, I examine the effects of trade mark registration on TCEs pertaining to Greek mythology and Romanian folklore. This section illustrates that TCEs may be blurred, tarnished or taken unfair advantage of in the same way as reputed trade marks. In the concluding section, I demonstrate how, inter alia, EU trade mark law ${ }^{1}$ may, via trade mark registration, permit TCEs to be appropriated and misappropriated. Because there are several angles from which appropriation can be viewed, there is some ambiguity surrounding the concepts of cultural appropriation and misappropriation. For the purposes of this article, I shall use the term 'appropriation' in a narrow and specific sense, namely the exclusive commercial exploitation of a TCE as a trade mark by an entity unconnected with the

\footnotetext{
1 The legal analysis herein contains references to the provisions of the First Council Directive 89/104/ EEC, Directive 2008/95/EC ('TMD 2008') and the Council Regulation (EC) No 207/2009 ('CTMR 2009') which have now been repealed and replaced by subsequent legislative acts, namely Directive (EU) 2015/2436 ('TMD 2015') and Regulation (EU) 2017/1001 ('EUTMR'). The TMD 2015 and the EUTMR have maintained the structure of the initial provisions analysed in this article. Therefore, the analysis covers the legal status quo of Member States' national trade marks and European Union trade marks.
} 
originating community with the result that the TCE becomes deprived of its original meaning [24, p. 197]. Similarly, I use the term 'misappropriation' as a type of trade mark use, encompassing TCEs either in their original form or in an adapted one, which 'falsely suggests a connection with the community concerned or brings the community into contempt or disrepute' [52, p. 57].

A major caveat of this article is that it only discusses those folkloric symbols, names of folkloric legends, characters and/or mythological figures etc. which are registerable as trade marks by virtue of their nature (this excludes, for example, those which cannot be represented graphically or in another suitable form on the public trade mark register). Additionally, the article does not address the debate surrounding whether it is appropriate to use the intellectual property rights ('IPRs') system as a legal regime apt to preserve and protect TCEs.

For ease of reference, the terms 'EoF' and 'TCE' shall be used interchangeably in this article although their meaning is not always the same. Furthermore, the term 'protection' shall be used in order to designate those actions aiming at prohibiting 'some form of unauthorized use of material by third parties' [54, p. 3]. The term 'safeguard' will be used on the other hand in order to refer to measures taken for the 'the survival of the TCE for future generations' [54, p. 3]. The difference between these two concepts is sometimes emphasized and considered important when addressing the situation of TCEs in the context of defining the scope of the legal instruments dealing with TCEs [54, p. 3]. Certain conclusions drawn regarding the potential negative effects of trade mark registration of TCEs are not based upon use of qualitative research methods, such as interviews with members of the communities where specific TCEs referred to in this article originated. Instead, I have tried to formulate an argumentation based upon the available literature, submissions of indigenous communities and fact-finding mission reports addressing similar issues. Lastly, the choice of the symbols presented in the section dedicated to case studies and the conclusions presented therein are not intended to speak on behalf of the communities, which regularly acknowledge those TCEs as pertaining to them. Likewise, these conclusions should not be regarded as a form of activism that fights the trade mark registration system against a more or less elusive 'capitalist harm'. The purpose of these examples is to demonstrate that under current EU trade mark law, it is possible for symbols having a folkloric significance to be registered by entities unrelated to this background, and to pinpoint the effects which such registration may have on the symbol's original meaning.

\section{Traditional Cultural Expressions: Meaning, Ambit and Controversies}

\subsection{An Attempt to Establish Some Generally Accepted Traits of TCEs}

One of the most salient predicaments, when examining TCEs, is to produce a definition able to encompass their complexity and ever-evolving nature [46, 64, 84, p. 3]. As further discussed below, various bodies have dedicated significant resources to drafting comprehensive definitions which might determine the boundaries of TCEs 
as objects of legal protection. The primary scope of this subsection is not to determine which of these various definitions is the most appropriate (even if I do analyse some of their deficiencies). Instead, I shall examine these definitions in order to establish the essential features of TCEs which are common to the ideologies of all these bodies and certain indigenous groups involved in this debate.

The 1985 Model Provisions for National Laws on the Protection of Expressions of Folklore Against Illicit Exploitation and other Prejudicial Actions ('Model Provisions') adopted jointly by the World Intellectual Property Organisation ('WIPO') and the United Nations Educational, Scientific and Cultural Organization ('UNESCO') define EoFs, in Sect. 2, as:

'productions consisting of characteristic elements of the traditional artistic heritage developed and maintained by a community of [name of the country] or by individuals reflecting the traditional artistic expectations of such a community'.

UNESCO's 1989 Recommendation on the Safeguarding of Traditional Culture and Folklore ('Recommendation') regards folklore as a body of traditional creations pertaining to a 'cultural community' which 'reflect its cultural and social identity'. According to the Recommendation, folklore may be expressed through mythology amongst other forms. WIPO, through its Intergovernmental Committee on Intellectual Property and Genetic Resources, Traditional Knowledge and Folklore ('IPGRTKF Committee'), has perhaps made the most visible developments in this area. In 2017, it released a document entitled 'The Protection of Traditional Cultural Expressions: Draft Articles' which, in Article 2, proposes two definitions for TCEs.

The first proposal is a rather lengthy definition which enumerates the basic features of TCEs: 'any form of [artistic and literary], [other creative, and spiritual,] [creative and literary or artistic] expression', 'tangible or intangible', 'expressed or illustrated' [79]. From the outset, this definition seems to allow a relatively large number of expressions to qualify for legal protection. However, the subsequent conditions contained in this article curtail the purview of legally protectable TCEs. Thus, in order to qualify as a TCE, the sign, symbol or expression must be 'expressed and maintained, in a collective context, by indigenous [peoples] and local communities', it has to represent 'the unique product of and/or directly linked with and the cultural [and]/[or] social identity and cultural heritage of indigenous [peoples] and local communities' and it must be 'transmitted from generation to generation, whether consecutively or not' [79]. This account of TCEs is open to objection because it utilizes concepts, such as 'social identity' or 'collective context', which not only do not have predetermined meanings, but which are also open to quite wide and variable interpretations. For example, one could question whether the last two remaining persons of an indigenous community who preserve TCEs would qualify as a 'collective'. The alternative definition proposed by Article 2 appears to be more relaxed in terms of legal requirements which need to be fulfilled by the TCE in question, indicating that TCEs:

'comprise the various dynamic forms which are created, expressed, or manifested in traditional cultures and are integral to the collective cultural and 
social identities of the indigenous local communities and other beneficiaries' [79].

Even though the term TCE is often used by WIPO interchangeably with the term $\mathrm{EoF}$, it is interesting to note that, as opposed to the Recommendation, none of these alternative definitions uses the term 'folklore' in order portray TCEs. One possible explanation for this omission is that "the use of the word "folklore" [47, p. 756] was challenged on the basis that developing countries considered it an archaism which imparted a negative overtone on TCEs as 'creations of lower or superseded civilizations'. For the sake of clarity, it is emphasised that the use of term 'folklore' in this article is in no way made pejoratively. The negative connotation which indigenous communities give to the term 'folklore' is closely connected to the critique that Western countries and their institutions use to curtail the boundaries of TCEs to tradition [64, p. 6]. By contrast, developing countries and native populations are said to have an extensive apprehension of these concepts [64, p. 6]. Specifically, those representing native cultures argue that TCEs should not be regarded as a different item than traditional knowledge [46, p. 99].

Hence, it may be argued that the way WIPO or UNESCO try to define TCEs is similar to a process of 'cultural learning' [23, p. 90]. Such a mechanism is objectionable because it impairs the communication of cross-cultural information from the source to its receiver owing to a series of political factors [23, p. 90], or even in some cases, because of the existence of conflicts of interest. For example, WIPO through its abovementioned IPGRTKF Committee, is the institution which advocates the protection of TCEs and defines their content and yet, at the same time, WIPO also oversees the registration of trade marks, including some which consist of TCEs. Furthermore, the attempt to introduce a duration for which 'the TCE would need to have been used for in order to be protectable' [80] is questionable, not least because it gives rise to issues such as the way the temporal criteria should be proved.

On the other hand, the alternative of increasing the influence that indigenous communities have over what should qualify as a TCE is preferable. This alternative is justified on the basis of their right to self-identification as a component of their right to self-determination recognized by Article 1 of the International Covenant on Economic, Social and Cultural Rights [1]. In this context, the right to self-identification cannot be exercised more efficiently than by offering these communities the possibility of defining the scope and subject matter of legal protection. Further justification is founded in the fact that it is these communities who experience the feelings and emotions attached to their continuing use of the TCEs, as shown in WIPO's Report on Fact-Finding Missions on Intellectual Property and Traditional Knowledge between 1998 and 1999 [78, p. 137]. In the same vein, the representative of the Tulalip Tribes, originating from Washington, identifies that these 'expressions are not simply expressions, but bound to governance, identity, dignity and integrity and woven into rituals, practices, spiritual beliefs, stories, practices, and ceremonies' [48, p. 6].

These feelings, although playing a pivotal role in the spiritual and cultural attachment of indigenous communities to TCEs, were 'lost in translation' when those outside these communities, including members of legal committees, attempted to 
describe them. And despite WIPO's efforts, through fact finding missions et al., to 'identify, as far as possible, the IP needs and expectations of TK holders' [78, p. 5], understanding such feelings and 'transcribing' them into legal documents proved a rather futile exercise.

In this regard, indigenous communities rightly opposed some of the restrictions imposed by WIPO as to what should count as 'protectable' TCEs. Members of the Tulalip Tribes stressed that placing 'limits as a condition of eligibility for protection of TCEs reflected a profound misunderstanding of the nature of TCEs and how they are created' [54, p. 8]. Moreover, since TCEs have a 'slowly evolving' nature, the process of determining 'when a particular variant of a TCE work was first created for the purpose of measuring time under the proposed eligibility criteria is very difficult' $[54$, p. 8]. Such dangerous misconceptions can be avoided through an effective collaboration with members of the respective communities, a collaboration that could be framed in a similar fashion to ethnographic research.

Clifford argues that the negative effects of political factors which interfere with 'cultural learning' in ethnographic research could be overcome by engaging with members of indigenous communities at a deeper level. Clifford refers to the work of well-known ethnographer, Geneviève Calame-Griaule in order to illustrate how a meaningful collaboration can generate a rather accurate account of such communities' understanding of their culture. Calame-Griaule documented the life and culture of the Dogon people of Mali and her research method involved the interaction with 'four key collaborators, giving hints of their personal styles and concerns' [23, p. 91]. This led to 'an authentic creation of "Dogon thought's need in expressing itself for dialectic, for an exchange of questions and answers that interpenetrate and weave themselves together (p. 17)"' [23, p. 91].

While issues arising from deciding which is the best way to 'legally' defining such protean concepts are yet to be resolved, it seems to be accepted by all stakeholders that TCEs carry a collective meaning allowing communities living in a certain territory to differentiate themselves from other communities. Despite the significance of WIPO's efforts in this respect, it is worth noting that the fact-finding missions aiming at determining the 'needs and expectations of traditional knowledge holders' [78] did not consider any European country. This approach is clearly flawed because it overlooks the obvious fact that indigenous communities exist in Europe too (e.g. the Basques, Catalans, Sámi) [64, p. 10] yet their relevance appears to have simply been ignored, which is something that undermines their legitimacy in this context in the eyes of the world's policy bodies. Nevertheless, as it will be demonstrated in the next sections, TCEs pertaining to the EU territory are valuable sources of inspiration for trade mark owners and they are subject to appropriation and misappropriation too.

Though less visible, the EU appears to have been concerned with the 'legal' faith of EoFs as evidenced by the 2000 Report on the International Protection of Expressions of Culture under Intellectual Property Law ('Report on Folklore') instructed by the European Commission. Although the Report on Folklore discusses the narrative of folklore as envisaged by the Recommendation and the Model Provisions, it does not favour a one-size-fits-all definition. Instead, it advocates an alternative: establishing distinct definitions [64, p. 10] depending on the scope of the definition 
[64, p. 10]. The Report on Folklore identifies four facets [64, p. 10] which purport to define the concept of folklore thus accommodating both the Western view and the perspective of indigenous communities. The analysis shows that folklore and its expressions are temporal, spatial, proprietorial and societal manifestations [64, p. 10], which vary depending upon the particular location of origin. The temporal facet recognises the fact that many TCEs are transmitted from 'generation to generation'. Additionally, even if such transmission does not occur, there appears to be a common understanding between WIPO, UNESCO and indigenous groups in the sense that TCEs represent a resource inherited from the past.

The societal factor encapsulates, inter alia, the aspect that TCEs are used as a form of self-identification among members of the same community, or between different communities, which is of quintessential importance to indigenous communities [4, p. 390]. The proprietorial element (i.e. the fact that TCEs belong and may be used by the communities which purportedly generate them) is also recognized by indigenous communities. However, it is regarded more as a "complex systems of regulating the use' [76] of TCEs, rather than like an exclusive rights system typically encountered in Western legal systems.

The proprietorial element is often criticized because it is considered that 'traditional stories, styles, designs, patterns' [82, p. 22] may not be the object of property, or if they are the kind of things that may be owned, challenges often arise in terms of who is the rightful owner [35, p. 20]. As Correa points out, the answers to these questions are of particular relevance in discussions concerning protection of TCEs (in the sense of 'asserting positive rights' over them) [53]. This article, however, does not seek to address the issues surrounding which positive protection regime is best suited for TCEs. Rather, its approach may be regarded as 'defensive' [53] in the sense that it seeks to analyse how EU trade mark law could (and arguably should) be interpreted to prevent the registration of TCEs as trade marks, and thus, avoid their appropriation and misappropriation. Hence, when I analyse the interaction between EU trade mark law and TCEs in the subsequent sections, I mainly consider the temporal, spatial and societal features of TCEs. Thus, the proprietorial aspect of TCEs will be limited to linking TCEs back to their originating community. Before delving in this analysis however, it is important to briefly explore various normative accounts underpinning the idea that the preservation of TCEs is desirable and/or justified in the first place.

\subsection{Reflections on the Need to Preserve Culture and Its Iterations}

Although this section is dedicated to investigating the reasons why TCEs should not be registered as trade marks, I begin my analysis by looking at some of the reasons why there is an appetite for using TCEs in trade-related activities. This will help us contextualize the discussion regarding the four facets of TCEs as per the previous section. It has been suggested that because economics is the driving force behind the idea that culture and thus its expressions are important [3, p. 135], concerns relating to the need to safeguard and protect TCEs only appeared after their economic value was discovered [49, p. 883]. From this perspective, it was the emergence of 
neo-liberalist practices of commodification which triggered the transformation of TCEs in cultural capital [35, p. 32]. Arguably, one of the main reasons why there is an appetite for registering TCEs as trade marks is that trade marks function as communication tools $[73,81$, p. 550] for consumers. Thus, if a TCE already enjoys a certain level of public recognition/awareness, registration as a trade mark may save the trade mark owner from having to invest additional time and resources in making the trade mark known to the public.

Moreover, a TCE's 'cultural associations' [31, p. 1023] makes it an attractive sign which explains why some trade marks owners desire to use and register TCEs [31, p. 1023]. In this sense, using trade marks consisting of TCEs may also exploit consumers' assumptions that each particular purchase is serving to define their own identity [55, p. 340]. From this perspective, trade marks consisting of TCEs are similar to trade marks for luxury products which 'focus on conveying information about the buyer' $[15$, p. 78$]$ rather than information on the goods and services on which the trade mark in question is attached.

Nevertheless, large scale commercial exploitation of TCEs may cause disruption between the place of origin of that TCE and the products embodying the TCE if such products are manufactured somewhere other than in the territory of origin of the TCE [35, p. 32]. Trade mark registration facilitates such disruption because the registered TCEs then 'come under the control of others' [19, p. 4]. A trade mark owner is under no obligation to produce the goods and services in the territory of origin of the TCE, so 'native people are no longer masters of their own traditions and identities' $[19$, p. 4] with the risk that 'outsiders will get a false picture of insiders' culture' [82, p. 25]. Additionally, not only is control over the use of TCEs potentially lost along the way, but also a trade mark owner's 'replication [of ceremony, music and graphic arts] threatens to strip cultural elements of their history and undermine their authenticity' $[19$, p. 6]. It follows that while economic reasons may justify the demand for positive protection of TCEs, the consequences of transforming TCEs in cultural capital pose the risk of altering their conceptual value.

From an aesthetics perspective, the attempt to preserve culture irrespective of its iterations is questionable because "principles of equal dignity militate against allowing one group of people to impose a form of life on the next generation' [3, p. 136]. According to Appiah, it would not, therefore, be fair to preserve TCEs for future generations as this would automatically dictate the way these generations must behave. Although there may be communities where the preservation of TCEs may lead to the imposition of more, or less, controversial lifestyles, this contention is not valid for all TCEs. Furthermore, protecting the original content of TCEs against practices that might alter their meaning does not automatically impose certain behaviours on the members of that community. Thus, the argument on which Appiah's critique is based is not applicable to the angle from which this article is written or to the message that it wishes to convey.

From a human rights perspective, it is argued that TCEs should be left outside the scope of any practice (such as trade mark registration) which may restrict the way in which they circulate or are used because any restriction may impinge upon freedom of expression [73, p. 356]. Underpinning this contention is the idea that the selfidentification feature of TCEs represents a manifestation of 'expressive diversity' 
[70, p. 185]. Thus, TCEs sometimes function as signs of high cultural value which are part of the continuous social dialogue enabling citizens to take part in an ideal of participative democracy' [25, p. 367]. Consequently, the content and connotations of TCEs may only be developed and disseminated in a free environment, without the fear that exclusive rights enforcement could be pursued against those who use TCEs [73, p. 356].

Lastly, compelling ethical arguments underpin the need to safeguard TCEs against misappropriation which may occur when TCEs are registered as trade marks, as will be demonstrated in section three below. First, trade mark use of a TCE may generate 'racist stereotypes' [24, p. 187]. An example of this is the case of certain US trade mark registrations owned by the Washington Redskins (an National Football League team) which perpetuated a stereotypical account of Native Americans as 'bloodthirsty, warlike savages' [24, p. 187]. These registrations, incorporating TCEs pertaining to the history of Native Americans, were used by their owner to achieve specific commercial goals via extensive sales of team merchandise for example. Such use does seem unacceptable from an ethical perspective [13, p. 75] given that it undermines the dignity of the communities to which these symbols belong to [13, p. 75]. Secondly, the notion of fairness which underlies the principle that one should not 'reap where they have not sown' (used as an ethical ground for the justification of the trade mark law system [14, p. 818]) supports the stance that TCEs should not be exploited by unrelated third parties through trade mark registration. In essence, a trade mark applicant who has not invested any of their own resources in enhancing the marketability of a TCE should not be permitted to 'reap' any of the benefits of trade mark registration arising from the popularity of the sign.

It follows that appropriation practices that also have the potential to alter the original meaning of TCEs, such as their registration as trade marks, are not justifiable based upon aesthetics, human rights and ethical arguments. With this in mind, in the next subsection, I examine the way issues related to the preservation of TCEs have been tackled through various legal instruments at the European level.

\subsection{A European Commitment to Safeguarding TCEs}

This subsection is devoted to a brief overview of the non-trade mark law provisions which aim to safeguard TCEs, albeit indirectly. The analysis in this section is not confined to EU legislation. It also refers to the jurisprudence of the European Court of Human Rights ('ECtHr') and treaties signed under the auspices of the Council of Europe. Before discussing the European framework for safeguarding TCEs, it is necessary to discuss the connection between EoFs and the concept of "cultural heritage'. This is needed not only because these two notions are somewhat entangled but also because EU and Council of Europe legislation both contain specific provisions which aim to preserve European cultural heritage rather than making any express reference to folklore or TCEs.

Pursuant to Article 167(2) of the Treaty on the Functioning of the European Union ('TFEU'), the EU undertakes an obligation to safeguard the 'cultural heritage of European significance'. A Council of the European Union document which 
identifies European cultural heritage as a source of sustainable development, defines 'cultural heritage' as a pool of 'resources inherited from the past' [28] deriving 'from the interaction between people and places through time' [28], 'constantly evolving' and valuable from a social, environmental and cultural perspective, among others. Thus, the Council of the European Union has adopted a rather utilitarian approach on the matter which focuses on safeguarding cultural heritage because this triggers social and economic benefits. The three characteristics of TCEs relating to time, space and social context discussed in the previous section are common to this definition's conception of 'cultural heritage'. We may conclude then, that European EoFs are part of Europe's cultural heritage [64, p. 9] and thus, are implicitly addressed under the TFEU.

The Council of the European Union adopted its definition for cultural heritage to be consistent with that contained in Article 2 of the 2005 Framework Convention on the Value of Cultural Heritage for Society CETS no 199 ('The Faro Convention') which is still open for ratification for the EU [27]. One of the Convention's highlights is its bold and unconventional definition of 'cultural heritage' which is considered to have a 'people-centred approach, and focuses on the people who construct, use and celebrate (or oppose) heritage' [39, p. 11]. This narrative of cultural heritage acknowledges that cultural objects are 'important because of the meanings and uses that people attach to them' [18, p. 115]. This is particularly aligned to the way in which some sociologists explain how brands are built with the help of 'the immaterial labour of consumers' [5, p. 235], thus emphasizing even more the shared features of TCEs and trade marked 'brands'. The Faro Convention contains certain provisions which may be of interest when analysing TCEs in light of EU trade mark law. Under Article 5 of the Faro Convention, the contracting states are invited to recognise 'the public interest associated with elements of the cultural heritage in accordance with their importance to society'. Additionally, while the economic value of cultural heritage is recognised by the Convention in Article 10, the parties to the convention are required by Article 3 to:

'take into account the specific character and interests of the cultural heritage when devising economic policies; and ensure that these policies respect the integrity of the cultural heritage without compromising its inherent values' [26].

Against this background, it could be argued that were the Faro Convention to be adopted by all EU Member States, its provisions would become mandatory and thus relevant when assessing the absolute grounds of refusal of trade marks under EU trade mark law, specifically in cases related to EU's public policy. To this end, the Faro Convention could be construed as a legal text expressly recognising the value of TCEs as part of the public policy of the Members States and thus they could be relied upon in order to elicit an extensive interpretation of the grounds of refusal relating to public policy as further discussed in section three below. Moreover, Article 4(1)(c) of the Faro Convention provides that 'the exercise of the right to cultural heritage may be subject only to those restrictions which are necessary in a democratic society for the protection of the public interest and the rights and freedoms of others' [26]. 
Considering that a trade mark application is a proprietary right because it gives rise to a 'bundle of financial rights and interests', ${ }^{2}$ it remains an open question which right should be given priority in case of conflicts between the right to cultural heritage and the right to private property. As a matter of principle, if the preservation of TCEs would be accepted as a matter of public interest, then the right to the exercise of cultural heritage would have to prevail.

When regarded as forms of expressive diversity, TCEs may be protected under the provisions of Article 10 of the Convention for the Protection of Human Rights and Fundamental Freedoms ('ECHR'). Article 10 provides that 'the right to freedom of expression shall include freedom to hold opinions and to receive and impart information and ideas without interference by public authority and regardless of frontiers'. These provisions have been construed as requiring state institutions to ensure that the expressive diversity is not affected by the rights of trade marks owners [70, p. 215]. While the EU per se has not acceded to the ECHR yet, this is expected in accordance with obligations to do so in the Lisbon Treaty (in Article 6). Nevertheless, all Member States are parties to the ECHR and therefore they are bound to observe Article 10 of the ECHR, if not as part of the EU law, then as part of their national laws.

It follows that unlike the laborious actions of WIPO or UNESCO, EU legislation has not sought to tackle the issue of protecting or safeguarding TCEs directly. However, TCEs represent an integral part of the cultural heritage of the EU which is considered an asset and protectable under the TFEU. Additionally, TCEs represent a manifestation of the freedom expression right guaranteed under the ECHR. The combined efforts of the EU and of the Council of Europe suggest that there is at least a theoretical commitment within Europe to preserve European TCEs. The next section investigates the breadth of protection that trade mark owners enjoy under the EU law. The purpose of section three is to provide evidence on how the exercise of trade mark rights might sometimes undermine a TCE's original meaning.

\section{Trade Mark Monopolies Under the EU Framework?}

\subsection{Controlling Trade Mark Meaning Under the EU Framework}

In this section, I argue that a trade mark owner secures full control over the meaning of their registered trade mark, even though this control is theoretically limited to use of that trade mark during the course of trade. I use the term 'control' to refer to the fact that trade mark owners enjoy the ability of prohibiting all others from using a sign similar or identical to their registered trade mark (subject to the fulfilment of certain other requirements). By excluding others from using the sign or trade mark in question, a trade mark owner receives a legal monopoly over the sign. This is the first step in the process of 'prohibiting allusive use of trade marks' [33, p. 137] and altering the original meaning of TCEs.

\footnotetext{
${ }^{2}$ As per the Court's interpretation in Anheuser-Busch Inc. v. Portugal [2007] E.T.M.R. 24, H2.
} 
Trade mark holders do not have the exclusive right to market certain goods/services per se [14, p. 813], rather they may only control the use of a particular range of signs (i.e. those identical or confusingly similar to the registered mark) in relation to those goods and services in the context of a trading activity. Thus, any use of that sign as a component of free speech or, for example, or for other non-commercial activities should not be affected by the exclusivity granted under trade mark law. Moreover, a trade mark owner's exclusive prerogatives are curtailed by several defences (non-infringing acts) under the EU framework allowing certain 'fair uses' of similar or identical signs [32, p. 102]. This might suggest that trade mark owners' control over the circulation of signs is not that powerful, and that it is unlikely that the alteration of the original meaning of a TCE which has been registered and used as a trade mark would occur. It might be reasonable to assume that other types of uses, for example, use of the TCE as a badge of allegiance by the community where it originated would be permitted, and that such use would potentially curb any commercial connotations which the trade mark owner establishes. However, drawing upon the main characteristics of TCEs, I explain how the 'use in the course of trade' limitation does little to preserve TCEs considering the broad rights of trade mark owners which provide them with a monopoly on the use of the sign registered as a trade mark. Then, I turn to the even more thorny issue of how trade mark law's 'anti-dilution' provisions could have an additional knock-off effect on the unfettered circulation of TCEs.

TCEs, which document the history and culture of the communities living in a specific territory, have a variety of meanings and purposes. For example, TCEs are sometimes used to show affiliation to, or support of, their community. For the Sámi people, indigenous in northern parts of Norway, Sweden and Finland, their traditional clothing (called 'gákti in Northern Sámi, mááccuh in Inari Sámi and määcca k in Skólt Sámi’ [59, p. 20]) represents more than just a way of covering one's body. One of the main roles of Sámi traditional clothing is to denote 'the person's Sámi origin' [59, p. 20]. Furthermore, the clothing is considered

'a cultural object that contains expressive intellectual capital with which an individual is able to communicate with other members of the community and which at the same time expresses the individual in relation to their community and the community in relation to the outside world' [59, p. 23].

If a company or individual from outside the Sámi community were to register a trade mark consisting of a Sámi TCE, certain subsequent uses of that TCE by members of the Sámi community could be prohibited, including the sale of traditional memorabilia in a museum shop. ${ }^{3}$ This is because trade mark owners can prohibit third parties from using a similar or identical sign, in the course of trade, in cases

\footnotetext{
${ }^{3}$ Sámi communities in various parts of Sweden, Finland and Norway promote their identity among other things via museums where they also offer for sale traditional objects and clothing. See in this respect the Vilhelmina museum at http://www.museum.vilhelmina.se/, the Sámi Museum in Inari, Finland at https ://siida.fi/en/about-us/or the Varanger Samiske Museum in Norway at http://www.varjjat.org/web/index .php?giella1=eng.
} 
where consumers are likely to be confused as to the origin of the products. It has been established that sale of goods which are to be used by the purchaser or end user as a badge of affiliation is a commercial activity included in the scope of the concept of 'use in the course of trade', and so such sale is considered to pave the way to infringement. ${ }^{4}$ In other words, even the 'slightest' commercial use of TCEs, which by their very nature convey an allegiance message in relation to the community where they had originated, could be subject to a legal prohibition.

Defenders of the trade mark regime might argue that in the situation outlined above, members of the Sami community could make use of one of the defences available under trade mark law, and thereby avoid infringement liability. The law does permit, for example, third parties to use non-distinctive signs or indications to describe the characteristics of goods without requiring the a trade mark owner's permission if such use is in accordance with 'honest practices in industrial and commercial matters'. Thus, members of the Sámi community could continue to use TCEs similar or identical to TCEs which have been registered as trade marks provided that their use is either purely non-commercial, or in accordance with said honest practices. As we have just seen, the concept of 'use in the course of trade' includes the use of a sign similar or identical to a registered trade mark as a badge of allegiance. Hence, it is defined in such a way to favour the rights of trade mark owners. The same is also true for the notion of 'use in accordance with honest practices in industrial and commercial matters'. According to the orthodox interpretation of 'honest practices', such activities represent 'the expression of a duty to act fairly in relation to the legitimate interests of the trade mark owner'. ${ }^{5}$ This presupposes however that the third party is, or must be aware, of the existence of the trade mark in question, of its owner and of the trade mark owner's legitimate interests. This is an assumption which unjustifiably burdens a community which would have no reason to wonder whether one of the TCEs that they have been using for a long period of time has later become a registered trade mark.

Additionally, the use of a TCE for decorative purposes is also at risk of falling under the trade mark owner's control, and thus faces the risk of being enjoined. Under the current approach, using TCEs to embellish goods may still count as a prohibited dilutive act when the public 'establishes a link between the sign and the mark'. ${ }^{6}$ This link might not arise when the sign is used as a 'pure embellishment' or for an 'entirely decorative' purpose, but this is difficult to discern for two reasons. First, 'the boundaries of pure embellishment depend solely on the perception

\footnotetext{
${ }^{4}$ In Arsenal Football Club plc v Matthew Reed [2002] I-10273 the CJEU considered that the use of a similar or identical sign by a third party as a badge of loyalty represents infringement even if that third party makes it clear that the products bearing the trade mark were not coming from the owner of the trade mark.

5 The interpretation of the meaning of 'honest practices' was laid down by CJEU in Bayerische Motorenwerke $A G(B M W)$ and BMW Nederland BV v Ronald Karel Deenik [1999] I—925.

6 In Adidas-Salomon AG and Adidas Benelux BV v Fitnessworld Trading Ltd [2003] I-12537 the CJEU explained that when the public 'establishes a link between the sign and the mark' even if the sign is used as a decoration, the anti-dilution provisions are still applicable. Conversely, it is submitted that where the sign is used 'purely as an embellishment' it is not able to cause the establishment of a connection in the mind of the public and such entirely decorative use is permitted under the anti-dilution provisions.
} 
of consumers' [40, p. 328]. Second, as most TCEs are affixed on traditional clothing or on household objects for decorative purposes [59, p. 24], there is no simple way to separate what counts as 'pure embellishment' from something that could be held to be trade mark infringement. For example, Romanian traditional attire involves the decoration of coats with patterns specific to each region of Romania. It is possible that these patterns, once registered as trade marks, later acquire a secondary 'commercial' meaning. In this case, those Romanian consumers who are familiar with the pattern's original connotation would also establish a link between the patterns used in a decorative way and the commercial origins of the products bearing the trade mark. It then becomes virtually impossible for consumers not to make a mental connection between the trade mark and the TCEs used as embellishments. In this sense, from a linguistic perspective Professor Alan Durant explains that 'there is no intuitive way of separating out a distinctive (secondary) meaning from a descriptive (primary) meaning for a given use of an 'acquired secondary meaning' trade mark' [33, p. 130]. Furthermore, because TCEs are already embedded in the public mind as a symbol of tradition, the required link between TCEs registered as trade marks and TCEs used for decorative purposes could be easier to establish than in the case of other signs which had no particular meaning before being registered as trade marks.

The extensive interpretation of the concept of 'use' and the difficulty in applying the 'honest practices' defence, discussed above, presents an even greater challenge for TCEs when the trade mark owner is able to claim that their mark is 'reputed' because of the nature and extent of their commercial use of the trade mark. Reputed mark owners, under the European trade mark law, enjoy additional protection against dilution. Unlike the standard 'traditional' level of trade mark protection, dilution protection applies against uses on the same, similar or even dissimilar goods, and without needing to show that consumer confusion is likely. Instead, trade mark owners must prove that any use (without due cause) of their reputed trade mark takes unfair advantage of, or is detrimental to, the distinctive character or the reputation of the reputed mark. This type of legal protection seeks, among other things, to preserve the image of the trade mark with reputation as the trade mark owner portrays it.

This development in trade mark law is explained by Lury, citing the work of Douglas and Isherwood. The latter posits that 'consumption is to do with meaning, value and communication as much as it is to do with exchange and economic relations' [58, p. 14]. Thus, the meaning of a trade mark, although not completely departing from the traditional 'origin' function of a trade mark (seen to signify the source and quality of the goods) came to embody 'a person's gut feeling about a product, service or organization' [63, p. 1]. Such feelings or 'future experiences and attachments' [6, p. 8] that consumers perceive in relation to a product, safeguarded via anti-dilution protection, are triggered by what can be regarded as 'the brand' [6, p. 8]. The point at which a brand name or logo coincides with an undertaking's registered 'mark' (especially where the registered trade mark contains a word element or a figurative element) marks the intersection between trade marks and brands, triggering the trade mark's metamorphosis from a sign indicating origin into an investment in 'hard equity' [51, p. 7]. At this point, the mark adds a different type of value to the product: a value in the 'form of immaterial capital' [6, p. 8] which trade mark 
owners are incentivised to protect. One immediate consequence is that "creating associations between products is becoming established as the exclusive prerogative of the trade mark owner' [57] not only because the trade mark owner has the possibility to do so but also because she is encouraged to.

Hence, anti-dilution protection poses significant risks with respect to how TCEs can be used after a TCE has been registered as a mark, particularly if the trade mark owner decides to create a different 'image' from the one which the TCE enjoyed before registration. Put simply, the original meaning of a TCE will be typically different from that which a trade mark owner would wish, else the owner would have no interest in relying upon the anti-dilution provisions. In this context, another danger arises from the possibility of trade mark owners to either prohibit or inhibit uses which previously took place. As Durrant explains, even if a trade mark owner eventually loses a trade mark infringement claim:

'the mere fact of litigation (even the threat of litigation) would have a chilling effect by opening up a new frontier of protective action against allusive use, analogous to proprietors fending off potentially generic use of their trade mark' [33, p. 137].

Lastly, the settled case law of the Court of Justice of the European Union ('CJEU') allows for logical deductions to be made when assessing the risk of detriment to the image of the reputed trade mark (e.g. detriment arising from the contrasting quality of the goods to which the marks in dispute are applied). This 'logical deductions' exercise establishes a low threshold for infringement, which may be carte blanche in the case of TCEs.

In this subsection, I have examined the way EU trade mark legislation grants trade mark owners exclusive rights which could create a monopoly over the meaning of TCEs that have been registered as trade marks. The analysis explains how, within the EU, registered trade marks enjoy extensive protection which would permit a trade mark owner from preventing the kind of uses which would preserve a TCE's original meaning. The broad scope of legal protection reflects a wider paradigm shift in the role and function of trade marks from merely 'a device for conveying otherwise indiscernible information concerning a product' [56, p. 371] to a 'valuable product in itself' [56, p. 371].

The current general state of affairs has led to extensive scholarly challenge [30, p. 342, 71, p. 46], particularly in relation to 'social and cultural concerns about the privatisation of words and phrases' [71, p. 60]. But concerns in the case of TCEswhich form part of the expressive discourse in a democratic society [70, p. 215] (as elucidated in the preceding sections of this article) — are at least as high as in the case of 'words and phrases of the English language' [71, p. 64]. Thus, when TCEs are used as registered trade marks, they become susceptible at the hands of private entities 'in pursuit of their own commercial ends' [43, p. 456] to removal from the pool of expressive resources which should be free for others to use. Such behaviour seems to serve no public interest because unlike copyright or patents, trade mark rights are not granted to reward creativity or innovation on the part of the rights holder [71, p. 64]. Therefore, it is reasonable to conclude that the EU trade mark law's current approach works in such a way that it may create harmful monopolies 
over the signs registered as trade marks, which impinge upon the unfettered use of TCEs, especially in cases of alleged blurring, tarnishment and free riding.

In the following subsection, adopting a semiotic account of how trade marks function as signs in the 'language of consumption', I explain how once a TCE is registered as a trade mark, the proprietor's monopoly as conferred by EU trade mark law contributes to their appropriation and misappropriation.

\subsection{Appropriation and Misappropriation Through Trade Mark Registration: Overstated or Overlooked?}

This subsection is concerned with the potential effects that trade mark registration of TCEs may have on their original meaning and dissemination, especially in terms of the commercial connotations that trade mark use elicits over the signs registered as trade marks. Here, I propose that trade mark use of TCEs contributes to cultural appropriation, which then paves the way to misappropriation. I begin the analysis with a brief account of the broad notion of cultural appropriation and the harmful and, allegedly, beneficial effects which may occur following the occurrence of cultural appropriation.

Potential illustrations of what some regard as cultural exploitation are easy to find. In 2015, Kylie Jenner was censured for 'appropriating black culture' when she decided to change her hair style to braids [9]. In 2017, the fashion house Alexander McQueen was accused of cultural appropriation too, by apparently 'creating' a jacket which resembled a traditional Ethiopian dress [17]. At the 2018 Resort fashion show, US designer Tory Burch's collection included a white coat featuring 'African-influenced' black motifs [67], later shown to be a close copy of a traditional Romanian $20^{\text {th }}$ century coat exhibited at the New York Metropolitan Museum of Art. Following an intense social media campaign instigated by organizations fostering traditional Romanian clothing, the design was removed from the designer's website, and Burch issued a statement acknowledging her original source of inspiration for the coat and correctly referencing the motif's Romanian roots [7].

The fact that popular celebrities and brands are now promoted via social media means that they face constant global scrutiny. This has triggered a new trend against 'cultural appropriation' in an effort to defend indigenous communities of former colonies' from the 'harms' of the Western world. This online 'battle' against cultural appropriation is no longer the preserve of traditional activists but has become a matter of concern for a wider public. Supporters of cultural appropriateness publicly disavow the conduct of those celebrities who are seen to endorse beauty techniques or couture inspired from minority native cultures. While as a matter of principle, such manifestations of civic spirit are commendable, the way in which 'cultural appropriation' is portrayed by the general public is likely both to blur its conceptual outline and generate exaggerated reactions. The above examples reflect a rather mundane and simplistic account of the term 'cultural appropriation', which Coombe describes as 'the practice of white elites stealing the cultural forms of others for their own prestige and profit' [24, p. 209]. This narrative inevitably endows this expression with negative connotations. However, the 'stealing of cultural forms from 
others' [82, p. 6] does not necessarily generate negative or offensive results, as will be briefly explained below. According to Young, in the sphere of art, cultural appropriation may also involve object appropriation (the practice of moving artefacts from their initial location to a different culture's location), content appropriation (stories or music are adapted by an artist pertaining to a different culture), style appropriation or even motif appropriation [82, p. 6]. Whereas object and content appropriation are accepted as morally difficult to justify because it is recognised that such acts are sometimes tantamount to stealing and may lead to harm including erosion of that community's distinctness [82, p. 25], he notes that other types of appropriation are seen as generally justifiable because the actions may generate new valuable artefacts [82, p. 25]. Young's explanation in this regard seems questionable because people assign different types of originality or artistic value to art objects.

Clifford claims that Picasso's Girl before a Mirror is a work inspired by tribal artefacts of Kwakiutl natives [23, p. 193], as so is the result of what might be regarded as 'cultural appropriation' today. However, the final piece is undeniably valuable from an artistic perspective: 'something new' [23, p. 148] was born 'in the presence of something exotic' [23, p. 148]. Additionally, the 'new thing' does not appear to offend or hinder the distinctness of the native community to which the inspirational TCE belonged. It follows that cultural appropriation to create new artistic expressions, which copyright law will then generally protect, can be justified because society at large may benefit from access to these new works, which may in turn stimulate further creativity. We shall shortly return to discuss whether the same justification applies equally to trade mark registration of TCEs. But before doing so, I shall provide a semiotic account of how trade marks function as signs in the 'language of consumption' [12, p. 43] since such account is most suited to explain how TCEs are susceptible of being deprived of their original meaning, and further misappropriated through the system of EU registered trade marks.

The main reason for choosing the semiotics narrative is that the structural theory of semiotics explaining how signs acquire meaning sharesf several common elements with the conditions for trade mark registration contained in the EU trade mark law and with the newly recognised advertising function of trade marks.

Specifically, trade marks are considered to fulfil an advertisement function which endows them with the power to deliver 'products and services from producers to consumers in the most effective way possible' [10, p. 131]. Most of the time, this practice involves the use of marketing research which allows companies to identify prospective users of their products and services [10, p. 132]. Marketing research is also referred to as 'applied semiotic research' [10, p. 133]. The former uses semiotic theories, which explain how signs acquire meaning, to ensure that trade marks used in advertising induce buyer associations [10, p. 153]. Just as a trade mark functions as a vessel for indicating the origin of products, similarly from a semiotic perspective, a sign may take any shape as long as 'someone interprets it as 'signifying' something — referring to or standing for something other than itself' [22, p. 13]. According to this view, the internal structure of a sign comprises of three elements [22, p. 13]: the 'sign vehicle' which is the form in which the sign is expressed, the 'interpretant' which stands for the 'the sense made of the sign' and an 'object' which is an item external to the sign to which the sign pinpoints to [22, p. 29]. 
These three elements may be found in the internal structure of the trade mark law [11, p. 624] as well. First, both the TMD 2015 and the EUTMR define trade marks as consisting of any signs capable of being represented on the register. Even if the condition that the sign needs to be capable of graphical representation has been recently waived in the EU trade mark law, the sign still must be able to be represented on the register in such a way that the subject matter of protection is clearly determinable. Therefore, the need for the sign to take a specific form is kept as condition for trade mark registration purposes. Thus, the necessity of being a 'sign vehicle' is a condition for trade mark registration too [11, p. 624]. The 'sense made of the sign' may be regarded [11, p. 624] as the requirement that the mark should be able to 'distinguishing the goods or services of one undertaking from those of other undertakings'. Finally yet importantly, the object of the sign is represented by the goods and services which the trade mark must distinguish [11, p. 624].

The meaning of the sign, from a semiotic perspective, is revealed by way of its interpretation rather than from its intrinsic content [22, p. 32]. If we were to apply this theory by analogy to trade marks, it would mean that the average consumer, the notional addressee of the trade mark, is revealing the meaning of the trade mark, taking into account the interplay between the three elements which compose the trade mark (i.e. its representation, the goods and services to which it refers and the ability of the trade mark to distinguish the origin of those goods or services to which it is applied).

Additionally, the semiotic narrative explains that the importance of a sign and its content resides in the interaction with other signs [22, p. 32]. Such explanation is compatible with the trade mark doctrine of 'acquired distinctiveness' or 'secondary meaning' $[24$, p. 64,43 , p. 231,62, p. 738$]$. According to the secondary meaning approach, descriptive signs which would normally not be entitled to trade mark protection (because they primarily function to convey information about what the goods are, rather than serving as an indicator of origin) may become distinctive over time, if buyer associations are created between the sign and the goods and services of the trade mark owner [62, p. 748]. TCEs already carry certain culturally significant meanings and this might lead to the conclusion that they could be regarded as descriptive for certain goods and services. However, the TCE would still be eligible for registration, but first, the trade mark applicant needs to create 'buyer associations' [62, p. 748] between EoFs and the goods and services for which trade mark protection is sought. In other words, once the advertising message attached to TCEs is likely to supersede TCEs original cultural meaning [73, p. 371], the TCE may be appropriated via trade mark registration.

It follows that once a sign is taken from its original system of relations and is introduced into a new one, the initial meaning and content of the sign changes as well. In the specific case of EoFs registered as trade marks, it is inevitable that their original meaning will change because they have become badges for commercial exploitation, rather than signs of purely social or cultural importance. Furthermore, trade mark owners are also able to educate the public with respect to the meaning of 'their' trade marks [24, p. 167] as vessels of certain 'brand values' or associations. Having regard to a trade mark's magnetism and its potential to become enmeshed in the public's perception with the products in relation to which it has been used [72, p. 384], Senftleben likens 
them to a 'black hole that absorbs all the communication surrounding' [72, p. 384]. Additionally, TCEs may be misappropriated when they are used in a 'wrong way' or in a stereotypical manner which may influence the image of certain groups [24, p. 188].

Despite existing compelling semiotic arguments explaining how trade mark registrations may alter the meaning of TCEs, the EU does not, apparently, share any concern that commercial exploitation may deprive TCEs of their original meaning. On the contrary, the European Commission has labelled the commercial exploitation of TCEs beneficial, even when such exploitation is undertaken 'by persons outside the region where the folklore originates' [37]. Surprisingly, the European Commission concludes that this stimulates 'cultural exchange' with the net 'benefit' that 'authentic expressions of folklore [...] become inherently better known and of higher economic value' [37]. What it is telling is that this conclusion is not supported by any method to gauge or assess how and to what extent any EU indigenous community has benefited from other's commercial exploitation of its TCEs. Moreover, use is 'considered offensive when it economically benefits the appropriator without producing any economic, cultural or social benefit to the originating community' [64, p. 19]. Even accepting the Commission's contention that the TCEs have suffered no harm from commercial exploitation, appropriation may still be undesirable considering that inappropriate use of TCEs may create insulting or offensive associations, as discussed in the previous sections [82, p. 26]. Unfortunately, the originating community cannot control any such negative connotations once the TCE has been registered as a trade mark.

As anticipated, while there is a case to be made for the good kind of appropriation in the arts or at least from a copyright law perspective because it may lead to 'the production of valuable works of art' [82, p. 26] the same is not applicable to trade marks. This is because the cultural features of TCEs are transformed into commercial ones following trade mark registration and thus they become 'a repository of value and meaning, which can be deployed across a wide range of products and services' [61, p. 1843]. Such transformation considers the business interests of the business owner, and in some cases the interests of consumers. Consequently, the cultural significance of the signs is completely disregarded since the role of trade marks is to sell and encourage consumption.

This subsection argued that appropriation occurs when a TCE obtains a secondary meaning following its association with a particular product or service [24, p. 197]. In certain situations, depending on the original meaning of the TCE in question and the precise way they are used, trade mark registration paves the way to misappropriation. In the following subsection I contend that while there is no express provision excluding TCEs per se from trade mark registration, there is scope to safeguard TCEs from appropriation and misappropriation under the current absolute grounds of refusal framework.

\subsection{An Ounce of Prevention is Worth a Pound of Cure}

The adage - 'An ounce of prevention is worth a pound of cure'-was apparently coined by Benjamin Franklin when trying to convince Philadelphians to invest in fire prevention and thereby avoid the potentially devastating results of fire [77]. The philosophy behind this 'proverb' has so far proved accurate with respect to 
the difficulty of 'curing' TCEs from the negative effects of trade mark registration. This is because, as I have shown above, the statutory limitations (i.e. post-factum defences or remedies) which EU trade mark law provides have not proved effective to curtail the scope of trade mark owner's monopoly when it comes to unfettered circulation of TCEs and their original meaning. In this subsection I investigate which mechanisms currently contained in EU trade mark law could be employed in order to prevent TCEs from being registered as trade marks in the first place, and hence ensure that they are not appropriated and misappropriated.

In trade mark law, 'absolute grounds' of refusal may be relied upon by examiners in registration offices or interested third parties in order to oppose, or otherwise challenge, registration of a sign based upon general concerns or public interests [14, p. 928]. There are challenges when relying upon these grounds of refusal because the notion of 'public interest' is somewhat mercurial, yet it is accepted that each ground of refusal 'must reflect different considerations' of this public interest. ${ }^{7}$ What is important to note is that despite EU's commitment to protect the 'cultural heritage of European significance', as discussed in the previous sections, none of the absolute grounds of refusal directly exclude EoFs from registration. Equally, 'signs with cultural significance' [73, p. 357] per se are not expressly excluded from trade mark registration either under EU law [73, p. 357]. Although it would seem desirable to have an express provision that specifically excludes such signs from registration, since this would avoid any ambiguities caused by hard-to-define concepts such as the 'public interest', EU trade mark law does include several absolute grounds which could be used to fill this gap. In the following paragraphs I explain why the exclusion of the TCEs from the registration may be justified as a matter of protecting the public interest.

First, current EU trade mark law excludes signs which are contrary to public policy or to accepted principles of morality from registration as trade marks. According to the Guidelines of the European Union Intellectual Property Office, the concept of 'public policy' at the level of EU reflects 'a common understanding of certain basic principles and values' which are contained in the body of 'EU law applicable in a certain area'. The preservation of the European cultural heritage to which TCEs originating on the European continent belong is desirable as it triggers social and economic benefits. In this sense, the TFEU specifically provides the obligation of the EU to protect the 'cultural heritage of European significance'. As we have seen, the registration of certain TCEs by an entity unconnected to the place of origin of the TCEs may undermine the TCEs' original meaning and may even generate offensive new meanings for the TCEs in question. Thus, an argument can be made in that such registration would contravene to EU's public policy objectives of preserving the cultural heritage of European origin.

An approach which seems to aim at preserving the original meaning of culturally valuable artefacts was adopted by the advisory opinion of the EFTA Court with respect to the works of art of the famous Norwegian artist Gustav Vigeland. Here the issue was whether some of Vigeland's works which lapsed copyright protection

\footnotetext{
${ }^{7}$ As per CJEU's rationale in P SAT.1 SatellitenFernsehen GmbH v OHIM [2004] I-08317.
} 
could be registered as trade marks by the Municipality of Oslo. In this case the Court opined that 'the risk of misappropriation or desecration of a work may be relevant' in deciding if such registration must be denied as per the absolute ground of refusal relating to the accepted principles of morality contained in the TMD 2008.

The territorial characteristic of TCEs which makes them cultural manifestations limited to certain regions or geographical areas of the Member States should not interfere with their belonging to the sphere of the European cultural heritage protected under the TFEU. This is because the notion of public policy, as per CJEU's ruling in Couture Tech Ltd v Office for Harmonisation in the Internal Market [2011], must be assessed in accordance with 'the particular circumstances of individual Member States which are likely to influence the perception of the relevant public within those States' and not solely considering those elements common to all Member States. That is to say, the public policy of one Member State is relevant when assessing the public policy of the EU as a whole. In the case of TCEs, adopting this line of reasoning would mean that those TCEs originating from one area of a Member State but which are regarded as culturally significant by communities outside that Member State may be regarded as European TCEs. Hence, it may be argued that the provisions relating to public policy exclusion may be used in order to prevent the trade mark registration of TCEs if such registration impedes, or is likely to impede, other rights provided by the legislation of the EU, including but not limited to the TFEU.

Trade mark law in New Zealand includes a refinement of the public policy and morality ground of refusal which aims directly at the protection of TCEs [41, p. 83]. This provision denies registration to signs that are offensive to a particular community from a cultural point of view [41, p. 83]. The notion of 'cultural offence' has replaced the phrase 'contrary to morality' in New Zealand's trade mark law [42], thus suggesting that the misappropriation of TCEs is not a completely different concept than undermining 'public morality'. Indeed, in New Zealand, the notion of 'cultural offence' encompasses a situation in which registration is sought for a symbol which ignores or defies the purpose for which that symbol is commonly used [41, p. 94]. Indeed, these provisions contained in New Zealand's trade mark law represent a considerable step forward [46, p. 84, 84] and if introduced in the EU trade mark law, such ground of refusal would prove quite beneficial for European TCEs.

The closest approximation that EU trade mark legislation has to 'cultural offence' is an optional ground of refusal covering registration of signs of high symbolic value, in particular religious symbols. For example, in Italy where this provision has been implemented, the Italian trade mark office must notify interested public authorities which have jurisdiction in this field (i.e. dealing with signs of high symbolic value) when such signs are included in trade mark applications [60, p. 214].

Even in jurisdictions where this ground has been implemented, there would be difficulties when applying it to TCEs, because the reference to 'high symbolic value' may not stretch to ordinary symbols with cultural significance [73, p. 358], as the law does not provide any benchmark for where and how the line between a symbol with a high symbolic value and one with a medium or low symbolic value should be drawn. Also, there is no explanation as to how the value threshold is to be determined. Is it qualitative or quantitative? For the symbolic value to be 'high', does this 
depend upon the number of people who regard a sign as valuable? Or on the effect and degree of reverence that the public, irrespective of its size, shows towards a certain sign?

A possible solution to the current law's lack of clarity would be to adopt a legal instrument that identifies and records those TCEs belonging to Member States' indigenous communities which are signs of high symbolic value. This seems like a viable option because the law does not impose special requirements in terms of what should qualify as a sign of 'high symbolic value'. A sociological account explaining how 'symbolic value is determined in relation to socio-cultural contexts' [36, p. 1] could prove useful in supporting the claim that TCEs enjoy high symbolic value in the communities where they originate. For example, for the Sámi people, their traditional clothing is not merely a functional object that serves the purpose of keeping a person warm. According to a report of the Finish Ministry of Education and Culture investigating the needs of the Sámi people with respect to the protection of Sámi TCEs, '[T]he use of traditional Sámi clothing is linked to significant moral values, such as an expression of the individual's identity and sense of belonging' [59, p. 21]. If we accept Durkheim's account of religion as 'a unified system of beliefs and practices [...] which unite into one single moral community called a Church [...]' [34, p. 48] then we must accept that morally valuable TCEs, such as Sámi clothing, are not significantly different from religious signs which are presumed by trade mark law to possess high symbolic value. Hence, morally significant TCEs should qualify for the exclusion provided for signs of high symbolic value.

Apart from their culturally relevant meaning, TCEs are important as 'cultural capital' [35, p. 32]. This may act as an incentive for some unrelated third parties to register TCEs with the sole purpose of later licensing the use of the sign. For example, the Norwegian bunad is a traditional folk costume consisting of hand embroidered details which may cost up to EUR 4000 [35, p. 27]. Eriksen explains that from an anthropological perspective, the 'economics of the bunad is deeply informed by cultural values and norms relating to tradition' [35, p. 27]. Hence, it is the public's cultural attachment to it what makes the bunad so much more expensive than other articles of clothing. From this perspective, TCEs may be seen as signs with 'added value' which can give rise to what Senftleben refers to as 'cultural heritage grabbing' [73, p. 358]. This practice of unrelated third party free-riding on symbols having cultural importance typically involves trade mark registration of the TCEs in order 'to impose an obligation on other traders to obtain licenses for its use' [73, p. 358]. While the public interest exclusion might not be fully applicable in this situation-for example if the trade mark applicant has no plan to alter the meaning of the TCE - this kind of conduct might arguably fall with the exclusion to registration of signs in bad faith.

In order to rely successfully on the bad faith exclusion, it is necessary to show that the trade mark applicant knew that the sign applied for was identical or similar to one which an indigenous community had been using for the same or similar goods, and that the applicant sought registration with the intention of prohibiting others including the community where the TCE originated from using that sign (as per the CJEU's guidance in Chocoladefabriken Lindt \& Sprüngli AG v Franz Hauswirth GmbH [2009] I-04893). In the case of TCEs, the requirement for prior 
use by the community where it originated is fulfilled, since TCEs have a temporal standing, and sometimes may even be qualified as 'a resource of the past'. As for the applicant's knowledge of the sign's cultural and folkloric connotations, this will often to be straightforward to establish since the chances of not knowing about the prior use of specific a TCE are rather remote, especially considering the speed of digital information dissemination, and readily available sources of public information. In relation to the intention to use the registration to prohibit third parties from using the protected mark in the future, then the intention to exclude others may be considered as tacitly manifested when a petitioner applies for the registration of a trade mark. After all, one of the main reasons why applicants seek to register trade marks is to secure the legal right to exclude others from using a similar or identical sign. In spite of bad faith often being considered only a 'general catch-all provision' [68, p. 392], I take the view that this provision may prove genuinely helpful for TCEs.

As has been analysed above, interested parties may successfully challenge, and registration office examiners may successfully refuse, registration of TCEs based on two grounds already contained in EU trade mark legislation. EU trade mark law governing national trade mark law seems to be more favourable for TCEs than that governing pan-EU rights because it allows Member States to enact a provision which more directly relates to TCEs, but this is also contingent upon those Member States recognising TCEs as signs having 'high symbolic value'. The prohibition on registration of signs made in bad faith has a wider scope of application, as a mandatory provision in both the TMD 2015 and EUTMR which therefore applies to all national and pan-EU trade mark rights.

\section{Trade Marks Consisting of TCEs}

So far, this article has, inter alia, established the definitions and characteristics of TCEs, outlined the EU's commitment to safeguarding TCEs and identified the potentially negative consequences which might entail from registering TCEs as trade marks. This section analyses two cases where TCEs have been registered as trade marks. These studies assume that these TCEs (as most are) are known by at least part of the public where the TCEs in question originate. Hence, the TCEs may be considered as possessing 'niche fame' which is the threshold which would make them eligible for anti-dilution protection under EU trade mark law, to prevent a reputed mark from suffering harm from blurring, tarnishment or freeriding [20, p. 92]. With this assumption in place, this section aims to show that, just like reputed trade marks, TCEs suffer from this type of harm too. However, while the trade mark infringement test requires a change (or at least a risk of change) in consumers' behaviour, we shall not consider this aspect because unlike registered trade marks, TCEs are not intended to determine consumers' purchasing choices. Therefore, this criterion is incompatible with the purposes of TCEs which, as previously shown, relate to self-identification, self-expression etc. 


\subsection{The Starbucks Siren: A Case of Cultural Tarnishment?}

The EU Intellection Property Office ('EUIPO') promotes the idea that 'Your trade mark tells customers who you are'. This subsection questions whether this contention is valid in the case of the siren logo which Starbucks has registered as an EU trade mark at the EUIPO.

The supernatural creatures that are sirens, or 'mermaids' as they are sometimes known, are portrayed in different forms and feature in many traditional stories around the globe. The oldest and most famous account of sirens may, perhaps, be found in ancient Greek writings. Homer's Odyssey (approximately 700 BCE) [66, p. 1] describes them as creatures that lured sailors to their death through their beguiling song. Despite a lack of precision in the Odyssey itself [74, p. 12], artists have typically depicted these sirens as women with a bird's tails [74, p. 12], as illustrated on the famous Siren Vase currently held in the collection of the British Museum. Subsequent Greek authors (including Ovid in the Metamorphoses) [74, p. 12] also embraced sirens into their works. Apparently possessing qualities which 'made the wisdom of the sage unnecessary' [74, p. 12], sirens were seen by Greek society at that time as a catalyst in humans' relationship with knowledge [74, p. 12]. Today, the definition of cultural heritage in the Greek legislation is very broad. It includes 'expressions, activities, knowledge and information, such as fables, customs, oral traditions' [50]. Based upon this definition, sirens could qualify as a Greek originating TCE.

Starbucks adopted the siren as the company logo in 1971. The graphical representation consists of a creature having a woman's upper body and a double fish tail. The Starbucks' website describes the figure as 'mysterious and alluring' [75]. Starbucks is the proprietor of various trade mark registrations for its siren logo including EUTM no 008517054 and EUTM no 000689786, both registered for a wide range of products including, but not limited to, ground and whole bean coffee, cocoa, tea, restaurants, cafes, cafeterias, musical sound recordings, electric espresso makers, electric wallets, billfold etc. EUTM no 008517054 covers the original version of the siren logo whereas EUTM no 000689786 covers the current version of the mark which updated the earlier form by adding a crown and covering the siren's breasts with her hair.

Before Starbucks' logo could achieve its 'indication of origin' function (essential for it to function as a trade mark), at least some of the original meanings of the siren figure would first have to have been changed. Additionally, Starbucks would have needed to create new consumer associations between the siren and its products which would weakened, if not completely extinguish, the relationship between the siren and its Greek mythology origin. Reframing this in terms of the trade mark concept of tarnishment, had the 'reputation' of the siren - as TCE-benefited from the same protection as a reputed trade mark does against denigration, then arguably, its association with such mundane activities as coffee retail etc. would be regarded as impermissible 'tarnishment' because of the negative impact on the image of a symbol portrayed by the Greek vision of enlightenment and transmission of knowledge. Additionally, the way the company sought to 'censor' the siren's breasts in the later version of the Starbucks' logo might also be regarded as offending the TCE, 
considering that nudity is a central element of ancient Greek art. While Starbucks' website features 'The Story Behind the Siren on Starbucks Anniversary Blend Coffee Packaging' [75] in which the company's senior designer sets out his view of the message which the siren's appearance conveys, neither he nor the Starbucks' corporate website feature any information explaining their Greek origins and history. Unfortunately, the fate of the siren is not unique, as Greek symbols and names have been successfully exploited and deprived of their original meaning before. As Senftleben rightly points out [73, p. 356], the general public are most unlikely to associate NIKE with the Greek goddess of victory, since the sportswear brand has achieved its purpose of creating origin significance for the purposes of trade mark protection.

\subsection{The Internet Meets the Dacian Woolf: A Case of Cultural Free-Riding?}

The case of the siren is not singular as it shares a common fate with Draco, a figure encountered in the myths and legends of the Dacian culture. The Dacians were an ancient civilisation that inhabited part of the territory known now as Romania from around 1800 BC [45, p. ix]. Along with the Getae, the Dacians are partially considered the ancestors of the Romanian people. Their rich cultural heritage ranging from myths about the afterlife [45, p. 103] to jewellery, art, and other objects is still cherished today. The Romans, under the command of Emperor Trajan, conquered the Dacians in 107 AD following two military campaigns [45, p. 73]. After the victory, Trajan commissioned Trajan's Column in Rome to represent 'a narrative of the Dacian campaigns' [29] depicting the numerous battles which took place and the ultimate victory for the Romans. Trajan's Column depicts the flag used by the Dacians when they were waging war. The flag embodies Draco: a mythical creature having the head of a wolf and the body of a snake [65, p. 127], also known as the Dacian Wolf. According to Romanian legend, Draco was a figure popular among military troops and those who used to worship the knight-gods [65, p. 127]. The significance of the Dacian Wolf is closely linked to the idea of courage, dignity and freedom [44]. The Dacian New Year is a pagan ceremony dedicated, inter alia, to the celebration of the wolf which takes place annually on November $30^{\text {th }}$ [44].

Bitdefender is a relatively well-known company founded in Romania which provides security and antivirus software all over the world. The company's trade mark portfolio includes several national and international figurative trade marks consisting of stylized versions of Draco including Cypriot trade mark no 82972 and international trade mark no 1090871. Unlike Starbucks, Bitdefender's official website does provide an overview of Draco's origins and meanings and it contains references to Trajan's Column and other artefacts which contain depictions of Draco [16]. The company also mentions that it carries on 'the standard of our Dacian ancestors as a symbol of courage, determination and victory in our fight against online threats' [16].

Although the company's action in giving credit about the history of Draco seems commendable as the fair thing to do, its trade mark registrations may still be considered to be a form of exploitation because they ride on the coat-tails of Draco's 
reputation. In this case, free-riding occurs because of a transfer of the positive image of Draco as portrayed in local legends and myths to Bitdefender's own products and services. In a similar vein, it could also be argued that Bitdefender's adoption of the image of Draco as a trade mark permits the company to 'benefit from its power of attraction, its reputation and its prestige' just as free-riding is depicted in L'Oreal S.A. v Bellure N.V. and others [2009] I-05185. Equally important in establishing a case of impermissible free-riding under trade mark law is that the unauthorised user has not paid any financial compensation to the trade mark owner, nor invested in its own marketing efforts. In the case at hand, Bitdefender did not contribute in any way to the creation of Draco's image 'as a symbol of courage, determination and victory' [16]. On the other hand, one may not disregard the fact that Bitdefender was, no doubt, required to invest certain resources into making its trade marks distinctive such that consumers associate the Draco trade marks with its products. Nevertheless, this expenditure does not exclude the fact the Draco legend provided cultural capital which contributed to Bitdefender's logo popularity and overall brand success.

\section{Conclusion}

TCEs must be considered based upon an internal perspective given the societal, temporal and territorial elements which contribute to these symbols' formation as culturally significant. However, the notion of culture is itself constantly evolving, based upon the 'dynamic, subjective and relative' [18, p. 115] nature of its component values. Recently, the notion of culture has, perhaps, lost its conceptual outline as there has been reconsideration of which elements, including aspects such as race, gender or ethnicity, should be regarded as essential for its creation [2, p. 190]. This may explain why the various legal definitions of TCEs fail to fully capture the complexity of these social phenomena. Nevertheless, inability to craft the 'perfect' legal definition should not be used as a pretext to permit the appropriation and misappropriation of TCEs by the registered trade mark regime.

Some commentators suggest that appropriation and misappropriation could be avoided if a separate IP-based regime was established to protect TCEs directly, however this proposition has continued to face serious challenges [4, p. 396, 49, p. 894]. A main criticism to this proposal is that legitimising property rights in respect of subject matter having such blurred boundaries and recognition standards [2, p. 223] would create complications which would outweigh any benefit. Additionally, an IPR regime presupposes that a rightful owner of the TCE in question exists. Even if the rightful loner presents itself, there is no guarantee that Western proprietary legal regimes would be able to understand how such ownership is conceived. As Brown points out [19, p. 191], in cases where the mystical beliefs of indigenous peoples had to be demonstrated, the observers were not able to comprehend other people's thinking or feelings [19, p. 191]. Nevertheless, if we accept that it is hard to make the case for ownership by a culture of motifs, patterns, or general plot types' [83, p. 222] than, a fortiori, EU trade mark law should not allow private entities to (effectively) 'own' certain TCE by use of trade mark registration. Thus, even if 'common IP rationales aiming to protect intangible goods fail when it comes to the protection 
of folklore' [49, p. 884], this should not mean that trade mark law should create a safe harbour for the appropriation and misappropriation of TCEs.

A less intrusive option might be to oblige trade mark owners to disclose the origin of the TCE which they use as a trade mark. Yet, this option may prove ineffective in cases where the origins of TCEs are disputed or insufficiently evidenced. In such complex cases, information about the possible origins of the sign could be presented in a manner that assists consumers to understand the uncertainty of the original meaning of the symbol in question. Such an approach, although not solving the problem of establishing the real origin of the symbol, is certainly preferable to the current situation where the trade mark owner may only present the public with information which educates them the commercial connotation of the TCE, when used as a trade mark.

EU trade mark law appears to bolster the appropriation of TCEs and in certain situations to the point of misappropriation. Here, misappropriation occurs when the TCE, which has been registered as a trade mark, acquires a secondary 'trade mark' meaning in line with the 'distinctiveness' requirements of EU trade mark law. Misappropriation may also occur when the trade mark TCE conveys a message to consumers which either denigrates the community which originated the TCE or one which is stereotypical. As the examples presented in this article demonstrated, misappropriation may even occur even beyond what some authors regard as histories of ‘colonisation, domination, and subjugation' [2, p. 192]. Once a TCE has been appropriated or misappropriated, then trade mark registration may, among other negative effects, become an obstacle which prevents consumers from appreciating the values of the community from which the TCE originated [69, p. 398]. This article has advanced the thesis that express provisions which preserve the right to freedom of expression and the right to culture should provide the backdrop against which the limitations of a trade mark owner's rights and the absolute grounds of refusal contained in the EU legislation should be construed. Both EU legislation and conventions signed under the auspices of the Council of Europe contain provisions which seek to preserve European cultural heritage of which TCEs form part. Even though the CJEU alone has jurisdiction to interpret EU law, ECtHR jurisprudence has been visibly influential in CJEU decisions involving fundamental rights [21]. Not only has 'the ECJ has mentioned the ECHR in 57 judgments' [38, p. 13], but that CJEU jurisprudence has also cited ECtHR decisions [38, p. 98]. Therefore, the ECHR and ECtHR jurisprudence are not only relevant in the context of protecting TCEs from appropriation and misappropriation, but should be considered when considering EU trade mark law.

This article proposes that adoption of express provisions which deny registered trade mark protection to TCEs may go some way to circumvent the need to establish ownership over certain TCEs while also preventing appropriation and misappropriation. This solution would be facilitated at the EU-level by the creation of databases including, if not all TCEs, at least the most well-know and unchallenged ones. The criteria for inclusion in such a TCE database might require that the TCE is recognized as culturally significant by a community located on the territory of the EU. The idea of preventing misappropriation and appropriation of TCEs by their removal from the pool of signs available for trade mark registration should be understood 
as an attempt to encourage free and unfettered dissemination of TCEs. Similarly, refusal to register a TCE as a trade mark to promote a single entity's commercial goals may be recognised as a way of preserving both the dignity of the communities to which they belong [19, p. 6] and the inherent values which TCEs embody. Trade mark law should not assist business to free-ride on the coat-tails of traditional cultural expressions.

Acknowledgements I wish to thank the following people for their support and most helpful comments during the process of researching and writing this article: Hyo Yoon Kang, Jose Bellido, Lynne Chave, Matt Fisher and the anonymous IJSL reviewers. The article is dedicated to the loving memory of my father.

Open Access This article is licensed under a Creative Commons Attribution 4.0 International License, which permits use, sharing, adaptation, distribution and reproduction in any medium or format, as long as you give appropriate credit to the original author(s) and the source, provide a link to the Creative Commons licence, and indicate if changes were made. The images or other third party material in this article are included in the article's Creative Commons licence, unless indicated otherwise in a credit line to the material. If material is not included in the article's Creative Commons licence and your intended use is not permitted by statutory regulation or exceeds the permitted use, you will need to obtain permission directly from the copyright holder. To view a copy of this licence, visit http://creativecommons.org/licen ses/by/4.0\%.

\section{References}

1. Anaya, J. 2017. Technical Review of Key Intellectual Property-Related Issues of the WIPO Draft Instruments on Genetic Resources, Traditional Knowledge and Traditional Cultural Expressions. WIPO Website https://www.wipo.int/meetings/en/doc_details.jsp?doc_id=360462. Accessed 28 April 2020.

2. Anderson, J.E. 2009. Law, Knowledge, Culture. The Protection of Indigenous Knowledge in Intellectual Property Law. Cheltenham: Edward Elgar.

3. Appiah, K.A. 2005. The Ethics of Identity. Princeton: Princeton University Press.

4. Arnesen, C. 2014. Protection of Traditional Cultural Expressions: An EU Perspective. Journal of Intellectual Property Law 9 (5): 389-396.

5. Arvidsson, A. 2005. Brands. A Critical Perspective. Journal of Consumer Culture 5: 235.

6. Arvidsson, A. 2006. Brands Meaning and Value in Media Culture. London: Routledge.

7. Associated Press. 2017. Romanians Angered by Designer Tory Burch's 'Faux Pas The Daily Mail. http://www.dailymail.co.uk/wires/ap/article-4599870/Romanians-angered-designer-Tory-Burch s-faux-pas.html\#ixzz4oLOFns00. Accessed 28 April 2020.

8. BBC News. 2014. Romania Election Surprise as Klaus Iohannis Wins Presidency BBC. http://www. bbc.co.uk/news/world-europe-30076716. Accessed 28 April 2020.

9. BBC Newsbeat. 2015. Kylie Jenner's Hair Causes Instagram Race Row. http://www.bbc.co.uk/ newsbeat/article/33503069/kylie-jenners-hair-causes-instagram-race-row. Accessed 28 April 2020.

10. Beasly, R., and M. Danesi. 2002. Persuasive Signs. The Semiotics of Advertising. Berlin: Mouton de Gruyter.

11. Beebe, B. 2004. The Semiotic Analysis of Trademark Law. UCLA Law Review 51: 621-702.

12. Beebe, B. 2008. The Semiotic Account of Trade Mark Doctrine and Trade Mark Culture. In Trademark Law and Theory-A Handbook of Contemporary Research, ed. G.B. Dinwoodie and M.D. Janis. London: Edward Elgar.

13. Bennett, C. 2010. What is this Thing Called Ethics?. London: Taylor and Francis.

14. Bently, L., and B. Sherman. 2014. Intellectual Property Law. London: Oxford University Press. 
15. Biagioli, M., A. Chander, and M. Sunder. 2015. Brands R us. In The Luxury Economy and Intellectual Property: Critical Reflections, ed. H. Sun, B. Beebe, and M. Sunder. Oxford: Oxford University Press.

16. Bitdefender. 2017. Our Story. Bitdefender website. https://www.bitdefender.com/?ctrsel=1. Accessed 28 April 2020.

17. Blake, I. 2017. Alexander McQueen is Accused of 'Cultural Appropriation' over a $£ 4,895$ black velvet jacket that looks VERY similar to a ceremonial gown from Ethiopia and Eritrea. The Daily Mail http://www.dailymail.co.uk/femail/article-4455754/Cultural-appropriation-row-Alexander-McQue en-jacket.html. Accessed 28 April 2020.

18. Bond, S., and D. Worthing. 2016. Managing Built Heritage: The Role of Cultural Values and Significance. New York: Wiley-Blackwell.

19. Brown, M.F. 2003. Who Owns Native Culture?. Cambridge: Harvard University Press.

20. Burrell, $\mathrm{R}$ and $\mathrm{M}$ Handler. 2016. Reputation in the European trade mark law: a re-examination. M. ERA Forum. https://link.springer.com/article/10.1007/s12027-016-0419-2. Accessed 28 April 2020.

21. Butti, E, 2013. The Roles and Relationship between the Two European Courts in Post-Lisbon EU Human Rights Protection. JURIST http://jurist.org/dateline/2013/09/elena-butti-lisbon-treaty.php. Accessed 28 April 2020.

22. Chandler, D. 2007. Semiotics: The Basics. London: Routledge.

23. Clifford, J. 1988. The Predicament of Culture. Cambridge: Harvard University Press.

24. Coombe, R.J. 1998. The Cultural Life of Intellectual Properties. Durham: Duke University Press.

25. Cornell, D. 1985. Toward a Modern/Postmodern Reconstruction of Ethics. University of Pennsylvania Law Review 133: 291.

26. Council of Europe. 2005. Convention on the Value of Cultural Heritage for Society. http://www.coe. int/en/web/culture-and-heritage/faro-convention. Accessed 28 April 2020.

27. Council of Europe. 2017. Chart of Signatures and Ratifications of Treaty 199_Council of Europe Framework Convention on the Value of Cultural Heritage for Society. http://www.coe.int/en/web/ conventions/full-list/-/conventions/treaty/199/signatures?p_auth=pu0YsCD3. Accessed 26 March 2020.

28. Council of the European Union. 2014. Council conclusions of 21 May 2014 on cultural heritage as a strategic resource for a sustainable Europe OJ C 183/36.

29. Curry, A. 2012. A War Diary Soars Over Rome National Geographic. http://www.nationalgeograp hic.com/trajan-column/article.html. Accessed 8 July 2017.

30. Davis, J. 2002. European Trade Marks Law and the Enclosure of the Commons. Intellectual Property Quarterly 4: 342.

31. Davis, J. 2004. A European Constitution for IPRs? Competition, Trade Marks and Culturally Significant Signs. Common Market Law Review 41: 1005.

32. Dinwoodie, G.B. 2009. Developing Defenses in Trademark Law. Lewis and Clark Law Review 13: 100-153.

33. Durant, A. 2008. 'How Can I Tell the Trade Mark on a Piece of Gingerbread?' Naming and Meaning in Verbal Trade Mark Signs. In Trade Marks and Brands an Interdisciplinary Critique, ed. L. Bently, J. Davis, and J.C. Ginsburg. Cambridge: Cambridge University Press.

34. Durkheim, E. 1915. The Elementary Forms of the Religious Life. London: George Allen \& Unwin Ltd.

35. Eriksen, T.H. 2004. Keeping the Recipe: Norwegian Folk Costumes and Cultural Capital. FOCAAL 44: 20.

36. Ekström, K. 2011. Symbolic Value. In Encyclopaedia of Consumer Culture, ed. D. Southerton. Thousand Oaks: Sage Publications.

37. European Commission. 2002. Written Submission on Folklore from the European Community and its Member States for the 3rd IPGRTKF Committee. https://www.wipo.int/edocs/mdocs/tk/en/wipo_ grtkf_ic_3/wipo_grtkf_ic_3_11.pdf. Accessed 28 April 2020.

38. European Parliament. 2012. Main Trends in the Recent Case Law of the EU Court of Justice and the European Court of Human Rights in the field of fundamental rights. http://www.europarl.europ a.eu/RegData/etudes/etudes/join/2012/462446/IPOL-LIBE_ET(2012)462446_EN.pdf. Accessed 28 April 2020.

39. Fairclough, G., M. Dragićević, L.Rogač Šešić, E.Auclair Mijatović, and K. Soini. 2015. The Faro Convention, a New Paradigm for Socially_And Culturally—Sustainable Heritage Action? Kultura Skopje 4: 9. 
40. Fhima, I.S. 2006. Embellishment: Trade Mark Use Triumph or Decorative Disaster. European Intellectual Property Law Review 28: 321.

41. Frankel, S. 2005. Third-Party Trade Marks as a Violation of Indigenous Cultural Property. Journal of World Intellectual Property 8: 83.

42. Frankel, S. 2008. Trademarks, Traditional Knowledge and Cultural Intellectual Property. In Trademark Law and Theory-A Handbook of Contemporary Research, ed. G.B. Dinwoodie and M.D. Janis. London: Edward Elgar.

43. Gaines, J.M. 1992. Contested Culture: The Image, the Voice, and the Law. London: BFI.

44. Ghinoiu, I. 2010. The Dacian New Year' Revista Clipa. http://www.revistaclipa.com/4497/2010/11/ permanente/anul-nou-dacic. Accessed 8 July 2017.

45. Giurescu, C. C. 1946. The History of the Romanians from the Oldest Times Until the Death of Alexandru the Good (1,432). The Royal Foundation for Literature and Art.

46. Graber, C.B., and M. Burri-Nenova. 2008. Intellectual Property and Traditional Cultural Expressions in a Digital Environment. Cheltenham: Edward Elgar Publishing.

47. Hanse, H.C., M. Blakeney, L.S. Lourie, P.E. Salmon, and C. Visser. 2002. Symposium on Global Intellectual Property Rights: Boundaries of Access and Enforcement, Panel II: The Law and Policy of Protecting Folklore, Traditional Knowledge, and Genetic Resources. Fordham Intellectual Property, Media \& Entertainment Law Journal 12: 753.

48. Hardison, P and Tulalip Tribes. 2017. The Unfocused Gaze. In Presentation for Seminar on TCEs.

49. Hilty, R. 2009. Rationales for the Legal Protection of Intangible Goods and Cultural Heritage. International Review of Intellectual Property and Competition Law 40: 883-911.

50. Kallinikou, D. 2005. Protection of Traditional Cultural Expressions or Expressions of Folklore. http://network.icom.museum/fileadmin/user_upload/minisites/icme/pdf/Conference_papers/20042005/ICME_2005_kallinikou.pdf. Accessed 9 December 2019.

51. Klein, N. 2005. No Logo. London: Harper Perennial.

52. Kongolo, T. 2008. Unsettled International Intellectual Property Issues. Alphen aan den Rijn: Kluwer Law International.

53. Krikorian, G., and A. Kapczynski. 2010. Access to Knowledge in the Age of Intellectual Property. New York: Zone Books.

54. Kuruk, P. 2017. Key Policy Issues on Intellectual Property and Traditional Cultural Expressions. WIPO https://www.wipo.int/edocs/mdocs/tk/en/wipo_iptk_ge_17/wipo_iptk_ge_17_presentati on_3kuruk.pdf. Accessed 9 December 2019.

55. Leach, J. 2008. An Anthropological Approach to Transactions Involving Names and Marks, Drawing on Melanesia. In Trade Marks and Brands an Interdisciplinary Critique, ed. L. Bently, J. Davis, and J.C. Ginsburg. Cambridge: Cambridge University Press.

56. Lunney Jr., G.S. 1999. Trademark Monopolies. Emory Law Journal 48: 367.

57. Lury, C. 2008. Trade Mark Style as a Way of Fixing Things. In Trade Marks and Brands an Interdisciplinary Critique, ed. L. Bently, J. Davis, and J.C. Ginsburg. Cambridge: Cambridge University Press.

58. Lury, C. 2012. Consumer Culture. London: Polity Press.

59. Mattila, T. 2018. Report: Needs of the Sami People for Intellectual Property Protection from the Viewpoint of Copyright and Trade Marks. Helsinki: Ministry of Education and Culture Finland.

60. Max Planck Institute for Intellectual Property and Competition Law Munich. 2011. Study on the Overall Functioning of the European Trade Mark System. http://ec.europa.eu/internal_market/indpr op/docs/tm/20110308_allensbach-study_en.pdf. Accessed 20 June 2017.

61. McKenna, M.P. 2013. The Normative Foundations of Trademark Law. Notre Dame Law Review 82: 1839.

62. McLean, W.F. 1993. The Birth, Death, and Renaissance of the Doctrine of Secondary Meaning in the Making. American University Law Review 42: 738.

63. Neumeier, M. 2005. The Brand Gap. Indianapolis: New Riders.

64. Palethorpe, S and S. Verhulst. 2000. Report on the International Protection of Expressions of Folklore under Intellectual Property Law. https://www.semanticscholar.org/paper/Report-on-the-Inter national-Protection-of-Expressi-Palethorpe-Verhulst/033c1e095f09d6c027dd662d8fc883cf313 40df6. Accessed 17 May 2017.

65. Pârvan, V. 1937. Dacia-The Ancient Civilizations in Carpato-Danube Regions. Academic Association "Vasile Pârvan".

66. Peraino, J.A. 2006. Listening to the Sirens: Musical Technologies of Queer Identity from Homer to Hedwig. California: University of California Press. 
67. Phelps, N. 2017. Resort 2018 Tory Burch Vogue. http://www.vogue.com/fashion-shows/resort-2018/ tory-burch. Accessed 28 April 2020.

68. Pila, J., and P. Torremans. 2016. European Intellectual Property Law. London: Oxford University Press.

69. Ruesch, M. 2008. Creating Culture: Protection of Traditional Cultural Expressions and Folklore and the Impact on Creation and Innovation in the Marketplace of Ideas. Syracuse Journal of International Law and Commerce 35: 369.

70. Sakulin, W. 2011. Trademark Protection and Freedom of Expression: An Inquiry into the Conflict Between Trademark Rights and Freedom of Expression Under European Law. Alphen aan den Rijn: Kluwer Law International.

71. Senftleben, M. 2009. The Trademark Tower of Babel-Dilution Concepts in International, US and EC Trademark Law. International Review of Intellectual Property and Competition Law 40 (1): 46.

72. Senftleben, M. 2011. Trade Mark Protection-A Black Hole in the Intellectual Property Galaxy? International Review of Intellectual Property and Competition Law 42 (4): 383-387.

73. Senftleben, M. 2015. Free Signs and Free Use: How to Offer Room for Freedom of Expression Within the Trademark System. In Research Handbook on Human Rights and Intellectual Property, ed. C. Geiger. Cheltenham: Edward Elgar.

74. Shankman, S., and S. Durrant. 2000. The Siren and the Sage. Knowledge and Wisdom in Ancient Greece and China. London: Cassell.

75. Starbucks. 2015. The Story Behind the Siren on Starbucks Anniversary Blend Coffee Packaging https://news.starbucks.com/news/starbucks-anniversary-blend-coffee-the-story-behind-the-siren. Accessed 28 April 2020.

76. Tulalip Tribes of Washington. 2003. Statement by the Tulalip Tribes of Washington on Folklore, Indigenous Knowledge, and the Public Domain. https://www.wipo.int/export/sites/www/tk/en/igc/ ngo/tulaliptribes.pdf. Accessed 9 December 2019.

77. Walsh, L. 2012. Ounce of Prevention, Pound of Cure. https://www.cam.ac.uk/research/news/ounce -of-prevention-pound-of-cure. Accessed 5 April 2020.

78. WIPO. 2001. Report on Fact-Finding Missions on Intellectual Property and Traditional Knowledge. http://www.wipo.int/edocs/pubdocs/en/tk/768/wipo_pub_768.pdf. Accessed 28 April 2020.

79. WIPO. 2017. The Protection of Traditional Cultural Expressions: Draft Articles. http://www.wipo. int/meetings/en/doc_details.jsp?doc_id=276220. Accessed 28 April 2020.

80. WIPO. 2017. Indicative List of Outstanding/Pending Issues to be Tackled/Solved. http://www.wipo. int/meetings/en/doc_details.jsp?doc_id=368103. Accessed 28 April 2020.

81. Wurtenberger, G. 2006. Community Trade Mark Law Astray or Back to the Roots! European Intellectual Property Law Review 28: 549.

82. Young, J.O. 2008. Cultural Appropriation and the Arts. Hoboken: Blackwell Publishing.

83. Young, J.O. 2009. Cultural Appropriation. In A Companion to Aesthetics, ed. S. Davies, K.M. Higgins, R. Hopkins, R. Stecker, and D.E. Cooper. New York: Wiley.

84. Zografos, D. 2010. Intellectual Property and Traditional Cultural Expressions. Cheltenham: Edward Elgar Publishing.

Publisher's Note Springer Nature remains neutral with regard to jurisdictional claims in published maps and institutional affiliations. 